\title{
A MUDANÇA NAS PUNIÇÕES E OS DIREITOS DOS APENADOS
}

\author{
CHANGE IN PUNISHMENTS AND THE RIGHTS OF THE JUDGED
}

\author{
Abrelino de Castro Bitencourt ${ }^{\mathrm{I}}$ \\ Alex Sandro Torbes Kessner ${ }^{2}$ \\ Dionatan dos Santos Duarte ${ }^{3}$ \\ Fabio Lopes Schwertz ${ }^{4}$ \\ Lucas Peixoto da Silveiras \\ Carla Pilling dos Santos ${ }^{6}$
}

RESUMO- Inúmeras foram as mudanças das punições de indivíduos que não cumpriam as regras e normas do convívio em Sociedade. No princípio, a punição era no corpo, através de torturas e mortes. Com o decorrer do tempo, foram modificadas, onde eram pra "alma", virando mais humanas, não utilizando de força física para o cumprimento das mesmas. Os Estabelecimentos Prisionais começam a serem construídos de forma em que se consiga controlar o apenado e dar toda assistência necessária. Porém, com o crescimento enorme do número de apenados, perdeu-se todo objetivo principal da cadeia, que seria ressocializar o preso. A falta de investimento e de preocupação do Estado tornou o sistema penitenciário um caos, onde os indivíduos são jogados dentro dos referidos Estabelecimentos e esquecidos, com pouca assistência e cuidado, aumentando cada vez mais o número de reingresso de apenados.

Palavras-chave: Punição. Penas. Estabelecimento Prisional. Direitos Humanos.

ABSTRACT-There were countless changes in the punishments of individuals who did not comply with the rules and norms of living together in society. In the beginning, the punishment was in the

\footnotetext{
${ }^{1}$ Graduado em Redes de Computadores pela Universidade Federal de Santa Maria, graduado em Segurança pública pela Uninter Policial Penal pela Seapen/SUSEPE.

${ }^{2}$ Graduando em Gestão Pública pela Universidade do Norte do Paraná - UNOPAR. Policial Penal pela Seapen/SUSEPE.

3 Técnico em Contabilidade pela Escola Técnica de Canguçu- ETEC; Bacharel em Direito pela Faculdade Anhanguera Educacional; Tecnólogo em Administração de Empresas pela Universidade Norte do Paraná UNOPAR. Especialista em Direito Notarial e Registral pela Fundação Luiz Flávio Gomes - LFG; e Especialista em Gestão Prisional pela Faculdade Vila Nova do Imigrante - FAVENI. Policial Penal pela Seapen/SUSEP.

${ }^{4}$ Graduado em licenciatura em História pela Ulbra São Jerônimo. Pós-graduado em Gestão Prisional pela Faveni. Policial Penal pela Seapen/Susepe.

5 Graduado em engenharia de produção pela faculdade Anhanguera educacional. Pós- graduado em Gestão prisional pela Faculdade Vila Nova do Imigrante - FAVENI. Policial Penal pela Seapen/Susepe.

${ }^{6}$ Graduada em Educação Física. Pós- graduada em Gestão prisional e inteligência policial pela FAVENI. E segurança pública e Gestão em serviços sociais e políticas públicas pela FAMART. Policial Penal pela Seapen/Susepe.
} 
body, through torture and death. Over time, they were modified, where they were for "soul", becoming more human, not using physical strength to fulfill them. Prison establishments are beginning to be built in such a way that it is possible to control the convict and provide all necessary assistance. However, with the huge increase in the number of prisoners, all the main objective of the jail, which would be to re-socialize the prisoner, has been lost. The lack of investment and concern of the State has made the prison system a chaos, where individuals are thrown into the said establishments and forgotten, with little assistance and care, increasing the number of reentry of convicts more and more.

Keywords: Punishment. Feathers. Prison establishment. Human rights.

\section{INTRODUÇÃO}

Esse trabalho versa sobre as punições, as quais, na antiguidade eram realizadas em atos públicos, onde os delinquentes eram humilhados perante a Sociedade, para que demonstrassem que o efeito causado pelo ato impróprio seria a própria vida, e repensassem se valeria a pena esse alto custo. Após esse período, as penalidades foram ficando mais humanas e o "espetáculo" foi sendo substituído pelo cumprimento das penas em estabelecimentos prisionais. $\mathrm{O}$ objetivo seria afastar o indivíduo do crime, visando à sua reinserção na Sociedade, e não matá-lo. Começou a ser observado o passado do apenado, as circunstâncias, se havia algum tipo de distúrbio mental, entre outros. A Lei de Execuções Penais - Lei 7.210/84 descreve o direito da pessoa privativa de liberdade e classifica os estabelecimentos prisionais. Esse trabalho 838 demonstra o descumprimento da referida Lei, a violação do direito do apenado, e a dificuldade dentro das penitenciárias, visto que não há investimento em recursos e uma insuficiência enorme de vagas, já que o Governo abandonou o sistema penitenciário.

\section{DESENVOLVIMENTO}

Até o final do século XVIII e no começo do século XIX, as punições referentes aos crimes cometidos pelos indivíduos eram realizadas através de atos públicos, em praças e locais onde a população assistia atentamente pessoas sendo punidas através de torturas, muitas vezes eram amarradas em cavalos e, posteriormente desmembradas, e após, seu corpo era consumido por fogo. Outras, por não seguirem as ordens da Igreja, a qual era muito forte, ou as do "Chefe" de sua aldeia eram queimadas em público e teriam suas cabeças decepadas pelos carrascos. Antes, eram humilhados e muitas vezes obrigados a pedir perdão publicamente por seus atos inadequados. 
Com o decorrer dos anos, as formas de punição formam ficando mais humanas, sendo o delinquente punido de uma forma diferente de castigo, que não custasse sua vida. Tendo a Justiça Penal uma nova era, onde cada um seria punido de acordo com seu crime.

É a época em que foi redistribuída, na Europa e nos Estados Unidos, toda a economia do castigo. Época de grandes "escândalos" para a justiça tradicional, época dos inúmeros projetos de reformas; nova teoria da lei e do crime, nova justificação moral ou política do direito de punir; abolição das antigas ordenanças, supressão dos costumes; projeto ou redação de códigos "modernos": Rússia, 1769; Prússia, I780; Pensilvânia e Toscana, i786; Áustria, I788; França, I791, Ano IV, I808 e I8ı.(FOUCAULT, 2014, p.13).

O espetáculo da punição pública vai tendo fim e sendo substituída por atos de administração ou de procedimento, sendo os condenados não mais expostos e ridicularizados, e sim, cumprindo penas em cadeias. Chegou um momento em que os carrascos e juízes eram confundidos com criminosos devido aos assassinatos cometidos na condenação de pessoas, sendo o julgado ficando um objeto de admiração e piedade.

Começa-se a pensar que o delinquente deve ser punido como forma de afastá-lo do crime e não matá-lo de uma forma humilhante diante de plateia. Procura-se reeducar, corrigir, muitas vezes ainda utilizando chicotes, mas tocando no corpo o mínimo possível, sendo o enclausuramento a pena, e o indivíduo obrigado a trabalhar e ficar privativo de liberdade.

Por efeito dessa nova retenção, um exército inteiro de técnicos veio substituir o carrasco, anatomista imediato do sofrimento: os guardas, médicos, os capelães, os psiquiatras, os psicólogos, os educadores; por sua simples presença ao lado do condenado, eles cantam à justiça o louvor de que ela precisa: eles garantem que o corpo e a dor não são objetos últimos de sua ação punitiva. (FOUCAULT, 2014, p.16).

Até mesmo quando o ser é condenado à morte, esses funcionários cuidam do bem-estar do mesmo, sendo o objetivo a morte, de uma forma rápida, sem tortura, sem espetáculo.

Muitas penas foram previstas nas leis criadas durante esse período de transição entre as punições no corpo e as passíveis de cumprimento em vida, passando a terem perda de um direito ou de bens. Muitos atos considerados crimes na antiguidade alteraram seu grau de gravidade, mas ainda há a divisão do proibido e permitido, e hoje são definidos por códigos. Conforme descreve Foucault (2014, p.22): “Em compensação, o objeto "crime”, aquilo a que se refere à prática penal, foi profundamente modificado: a qualidade, a natureza, a substância, de algum 
modo, de que se constitui o elemento punível, mais do que a própria definição formal.” Desta maneira, começou a ser observado o passado dos réus, as circunstâncias que ocasionaram o fato, se houve vontade na prática do delito, o envolvimento de emoções, as enfermidades, visando a entender se haverão outros possíveis crimes e se o mesmo poderá ser reintegrado à sociedade após o cumprimento da sentença estabelecida, ou até mesmo antes, por medida de segurança deixá-lo recolhido em um Estabelecimento Prisional, até que seja concedida sua pena. Assim, neste momento, as punições começam a serem estabelecidas, também, sobre o indivíduo e não somente pela infração, julgando a "alma" do criminoso. Na Idade Média o objetivo era exato: quem foi? $\mathrm{O}$ que fez? E, por conseguinte, aplicar uma sanção dentre a legalidade. Com a mudança tenta-se entender o porquê, se foi algum distúrbio causado por doença, emoção, delírio, etc., assim pensando em uma forma de penalizar de acordo com o diagnóstico realizado.

No princípio, tendo a alegação que o autor era louco, o crime desaparecia, já que era retirado do poder da justiça. Porém, mais tarde, foi admitido que o autor poderia ser culpado e louco, mas deveria ser enclausurado e tratado, pois era doente, não devendo ser punido da mesma forma que os outros. As penas não foram observadas somente como culpa e sim, peritos psiquiátricos analisavam o indivíduo para esclarecer se a mesma deveria ser cumprida em hospícios ou prisões, o tempo de permanência, o tratamento, etc. Buscando, assim, que a pena 840 seja humanizada, com o objetivo de reintegração social, e não somente como punição.

Os tipos de crimes violentos começam a perder proporção perante os de propriedade, o roubo, entre outros, visto que os homens são levados a impulsos, são mal alimentados, tendo o uso de menor força do que o utilizado anteriormente para tentarem passar despercebidos. Os crimes foram ficando mais suaves antes da suavização das leis. Esse fator se deve ao crescimento demográfico, o aumento de riquezas e propriedades, sendo necessária que a justiça se torne mais severa.

As penas começam a ser calculadas de acordo com o crime cometido, devendo passar aos outros as desvantagens que eles resultam, e não as vantagens conseguidas pelo ato. As penas devem ser claras para que as pessoas possam distinguir entre o certo e o errado perante a lei, não deixando passar a ideia de impunidade pelo crime cometido. Mas, o que acontece é diferente do objetivo, nas prisões os apenados se ligam a outros fortalecendo o crime, as facções. Muitas vezes, entram por um determinado crime, e sem poder para se protegerem dentro dos 
estabelecimentos prisionais acabam se aliando a outros, visando à proteção e também seu sustento, visto que as facções possuem um poder gigantesco tanto na "guerra" quanto no financeiro.

O Estado é falido no âmbito penitenciário, faltando aos detentos o mínimo de assistência, tanto quanto a parte médica e alimentar, fazendo com que necessitem de ajuda de outras pessoas, muitas vezes as famílias não possuem condições financeiras para enviar comida, medicamentos, roupas, e também para visitá-los na prisão.

Como se vê atualmente, o sistema prisional está superlotado, falido, abandonado pelo Governo, os apenados são “jogados” dentro destes estabelecimentos, não havendo ajuda alguma, assim, foge-se do objetivo principal que seria a ressocialização dos apenados na sociedade. Tornam-se mais fortes e determinados a cometer outros crimes, visto que ficam cada vez mais revoltados, e possuem apoio para prática dos delitos.

Conforme consta no artigo 4I, da Lei de Execuções Penais - Lei 7.210/84, os direitos dos presos seriam:

\footnotetext{
"Art. 4I - Constituem direitos do preso:

I - alimentação suficiente e vestuário;

II - atribuição de trabalho e sua remuneração;

III - previdência social;

IV - constituição de pecúlio;

$V$ - proporcionalidade na disposição do tempo para o trabalho, o descanso e a recreação; VI - exercício das atividades profissionais, intelectuais, artísticas e desportivas anteriores, desde que compatíveis com a execução da pena;

VII - assistência material, à saúde, jurídica, educacional, social e religiosa;

VIII - proteção contra qualquer forma de sensacionalismo;

IX - entrevista pessoal e reservada com o advogado;

$X$ - visita do cônjuge, da companheira, de parentes e amigos em dias determinados;

$X I$ - chamamento nominal;

XII - igualdade de tratamento, salvo quanto à exigência da individualização da pena;

XIII - audiência especial com o diretor do estabelecimento;

$X I V$ - representação e petição a qualquer autoridade em defesa de direito;

$X V$ - contato com o mundo exterior por meio de correspondência escrita, da leitura e de outros meios de informação que não comprometam a moral e os bons costumes.

Parágrafo Único: Os direitos previstos nos incisos V, X e XV poderão ser suspensos ou restringidos mediante ato motivado do diretor do estabelecimento".
}

Porém, o que acontece é o descumprimento da Lei, violando o direito garantido as pessoas privadas de liberdade, as deixando cumprirem suas penas esquecidas pelo Estado e pelas pessoas, não objetivando sua reinserção à Sociedade de forma digna e respeitosa. Os 
delinquentes deveriam ser separados de acordo com o cumprimento de suas penas, devendo essas serem individuais, como medida de segurança e sua periculosidade.

Na Lei de Execuções Penais, também são classificados os estabelecimentos penais como: a) Penitenciária - destinada aos condenados à pena de reclusão, em regime fechado (Art. 87); b) Colônia Agrícola, Industrial ou Similar - são estabelecimentos construídos para abrigar os presos de justiça cujo cumprimento da pena seja em regime semiaberto (Art. 9I);

c) Casa do Albergado - destina-se aos presos de justiça cujo cumprimento de pena privativa de liberdade seja em regime aberto e a pena de limitação de final de semana. Nesses estabelecimentos os presos trabalham normalmente durante o dia e recolhem-se à noite (Art. 93);

d) Hospital de Custódia e Tratamento Psiquiátrico - são estabelecimentos destinados aos inimputáveis e semi-inimputáveis (Art., 99), ou seja, as pessoas portadoras de doença mental ou desenvolvimento mental incompleto ou retardado, desde que comprovado que o agente era portador dessa doença quando da prática da transgressão criminal e que era inteiramente incapaz de entender o caráter ilícito do fato. (Art.26);

e) Cadeia Pública - são estabelecimentos prisionais construídos próximos de centro urbano destinado a presos provisórios, ou seja, antes da sentença condenatória definitiva (Art.102);

Porém, o constatado é que há um aumento da prisão preventiva, déficit também de vagas para o cumprimento de regime semi aberto, delinquentes com transtornos mentais cumprindo penas em celas com detentos provenientes de outros crimes, uma falta total de cuidado para que possam cumprir seu castigo de uma forma correta, tendo como objetivo somente reparar o mal que fizeram pra sociedade.

Essa falta de separação por tipo de crime, muitas vezes torna "pequenos" criminosos em alvo das grandes facções, pois essa vulnerabilidade mostra que o retorno que eles tiveram foi pequeno perto do que poderão alcançar cumprindo a mesma penalidade, com crimes de maior potencial, visto que a pena não é calculada em função do crime, e cumprida no estabelecimento adequado. O crime começa a ser visto como vantagem, pois a pena não causa desprazer, sofrimento, e sim já premeditam um próximo objetivo quando voltarem à sociedade, e assim os apenados se tornam reincidentes no sistema carcerário. $O$ castigo não possui o mesmo peso 
para todas as pessoas, esse deve ser calculado de acordo com o criminoso e sua maldade, se houve emoção, se foi premeditado, não generalizando a função punitiva.

De um lado, o criminoso designado como inimigo de todos, que têm interesse em perseguir, sai do pacto, desqualifica-se como cidadão e surge trazendo em si como que um fragmento selvagem de natureza; aparece como o celerado, o monstro, o louco talvez, o doente e logo o "anormal".

É esse título que ele encontrará um dia sob objetivação científica, e o "tratamento" que lhe é correlato. De outro lado, a necessidade de medir, de dentro, os efeitos do poder punitivo prescreve táticas de intervenção sobre todos os criminosos, atuais ou eventuais; a organização de um campo de prevenção, o cálculo dos interesses, a entrada em circulação de representações e sinais, a constituição de um horizonte de certeza e verdade, o ajustamento das penas a variáveis cada vez mais sutis, tudo isso leva igualmente a uma objetivação dos crimes e criminosos. (FOUCAULT, 2014, p. Ioo).

Pelo que se observa hoje, as penas são somente para afastar os indivíduos da sociedade, não existindo uma Política Penitenciária voltada a condição humana do apenado, há uma carência em tudo, são jogados na miséria e abandonados dentro das penitenciárias, não havendo uma segurança pessoal e jurídica.Os direitos à alimentação, higiene, local salubre, são violados devido a cadeias superlotadas, não cuidando da integridade do apenado, visto que muitas vezes não são vistos como seres humanos em virtude de seus atos.

Não somente os delinquentes são esquecidos, os próprios agentes de segurança vivem nesses estabelecimentos insalubres, com falta de condições de trabalho dignas, baixos salários, falta de materiais, de efetivo e apoio diante do aumento da massa carcerária, a qual cresce em um ritmo incessante, tornando o sistema cada vez mais vulnerável. Com cadeias superlotadas, o tratamento ao indivíduo que cumpre pena se torna mais rigoroso, tendo que usar muitas vezes a rigidez em suas palavras e atos para atingir o controle da cadeia, onde essa possui os dominantes e os submissos, evitando motins, mortes. A importância da palavra torna-se imensa, pois há muita conversa entre Agentes e presos, onde se busca o respeito e apoio mútuo.

A falta de investimento em recursos e a insuficiência de vagas são os principais fatores para a catástrofe desse Sistema. Mas há que se pensar em prevenção do delito. Não só a demonstração do poder do Estado deve ser o principal objetivo, é preciso mostrar que as penitenciárias são lugares para cumprir pena e ressocializar, uma oportunidade de recomeçar de uma forma íntegra. Seria necessário capacitar os apenados para reinserção no mundo como um cidadão, visto como um ser humano, criando oportunidades no mercado de trabalho, não 
os deixando excluídos e marcados somente como delinquentes. É preciso reensinar os detentos que a pena modifica, transforma, e que ele pagaria pelo crime que lesou ao outro, e voltaria à Sociedade sem o desejo de cometer outro delito.

\section{CONCLUSÃO}

O objetivo deste trabalho foi demonstrar que apesar da mudança nas punições, onde o corpo era o principal objeto de punição, e hoje é o enclausuramento do indivíduo, melhorou com o decorrer do tempo, visto que no Brasil não existe pena de morte, há muito que melhorar, pois com o número crescente de apenados e a falta de investimento do Governo deixou os referidos delinquentes abandonados e sem assistência necessária. Apesar, da criação da Lei de Execuções Penais que garante direito ao indivíduo em privação de liberdade, não há cumprimento da referida Lei, há falta de investimento e preocupação com o detento, dando maior espaço para o crime organizado captar membros para suas facções, visto que muitos dos que são recolhidos estão sendo sustentados e apoiados por essas organizações.

Enquanto não forem cumpridas as Leis que garantem o mínimo aos apenados, tanto no direito à alimentação adequada, serviços jurídicos, médicos, psicológicos, entre outros, haverá cada vez mais um descontrole no sistema penitenciário e o aumento da criminalidade. Há de se pensar em ressocializar o apenado para sua reinserção na Sociedade, lhe capacitando com trabalho e regras, mas não é o que acontece. Cada vez que saem da cadeia se tornam mais marcados no mundo do crime, e pouco aceitos no mercado de trabalho, ficando mais uma vez esquecidos pelo Estado, e aumentando a chance de seu retorno para o estabelecimento penal.

\section{REFERÊNCIAS}

ALENCAR, Heloisa Costa Pacheco. O papel dos líderes nas organizações. Chefe, Minas Gerais, Belo Horizonte, 2015

CAMPOS, Vitor Luciano. Os estilos de liderança. FGV, Rio de Janeiro ,2ª edição, 2015

CHIAVENATO, I. Administração. 2.ed. São Paulo: Makron-Books, 1994. 522 p.

FONSECA, F.C. P. O curso de Administração Pública. FGV/8ı: percurso, sugestões e dilemas. São Paulo: Eanes/FGV, 2008. (Relatório de pesquisa, 05) 
LIMA, Rafael Medeiro de. As atribuições de um líder. Saraiva, São Paulo, 2015

RAMOS, Relida S. Liderando com inteligência emocional. Rio de Janeiro: Alta Books, $2^{\underline{a}}$ edição, 2014 .

SOUSA, Daniele Alves. Inteligência Emocional no Trabalho. Liceu. 20I4. Disponível em < http://repositorio.uniceub.br/bitstream/235/4955/I/2055020-6.pdf>Acesso em: I8 de agosto de 2019

TORRES, P. As características do poder. São Paulo: Linear Tecnologia e Serviços, 2017. 